\title{
Tobacco industry denormalisation as a tobacco control intervention: a review
}

\author{
Ruth E Malone, ${ }^{1}$ Quinn Grundy, ${ }^{1}$ Lisa A Bero ${ }^{2}$
}

${ }^{1}$ Department of Social and Behavioral Sciences, School of Nursing, University of California, San Francisco, CA, USA 2Department of Clinical Pharmacy, School of Pharmacy, and Institute for Health Policy Studies, School of Medicine, University of California, San Francisco, CA, USA

\section{Correspondence to} Prof Ruth E Malone, Department of Social and Behavioral Sciences, School of Nursing, University of California, San Francisco, 3333 California St, Suite 455, San Francisco, California 94118, USA: ruth.malone@ucsf.edu

Received 20 April 2011 Accepted 24 August 2011
ABSTRACT

Objective To conduct a review of research examining the effects of tobacco industry denormalisation (TID) on smoking-related and attitude-related outcomes.

Methods The authors searched Pubmed and Scopus databases for articles published through December 2010 (see figure 1). We included all peer-reviewed TID studies we could locate that measured smoking-related outcomes and attitudes toward the tobacco industry. Exclusion criteria included: non-English language, focus on tobacco use rather than TID, perceived ad efficacy as sole outcome, complex program interventions without a separately analysable TID component and non peerreviewed literature. We analysed the literature qualitatively and summarised findings by outcome measured.

Results After excluding articles not meeting the search criteria, the authors reviewed 60 studies examining TID and 9 smoking-related outcomes, including smoking prevalence, smoking initiation, intention to smoke and intention to quit. The authors also reviewed studies of attitudes towards the tobacco industry and its regulation. The majority of studies suggest that TID is effective in reducing smoking prevalence and initiation and increasing intentions to quit. Evidence is mixed for some other outcomes, but some of the divergent findings may be explained by study designs.

Conclusions A robust body of evidence suggests that TID is an effective tobacco control intervention at the population level that has a clear exposure-response effect. TID may also contribute to other tobacco control outcomes not explored in this review (including efforts to 'directly erode industry power'), and thus may enhance public support and political will for structural reforms to end the tobacco epidemic.

\section{INTRODUCTION}

Population level interventions have demonstrated over the past two decades that measures altering the social context of tobacco use can significantly reduce smoking prevalence. ${ }^{1-4}$ Tobacco industry denormalisation (TID), a focus of several successful tobacco control initiatives in the US and elsewhere, is increasingly regarded as essential to effectively addressing tobacco at the population level. Beginning with the "vector analysis' which first emphasised tobacco industry activities, rather than smokers' individual behaviours, as critical for tobacco control, a focus on the supply side in advocacy, research, policy and programme planning has appeared. ${ }^{2}$ 6-8 This emphasis, represented in specific provisions in the World Health Organisation's Framework Convention on Tobacco Control (FCTC), ${ }^{9}$ has not been universally embraced. In some countries, efforts still focus primarily on health education and prohibitions on youth tobacco sales. Some TID efforts have met with aggressive tobacco industry responses, occasionally including lawsuits aimed at curtailing them. ${ }^{10} 11$

Mahood $^{12}$ distinguishes between the denormalisation of tobacco use (which focuses on the addicted individual) and the denormalisation of the industry, arguing that only the latter offers the prospect of addressing the chief structural cause of the tobacco disease epidemic: industry activity. In this paper we use 'tobacco industry denormalisation' to mean themes, campaigns and perspectives aiming towards the reversal of the process of industry normalisation promoted by cigarette manufacturers for decades'. ${ }^{12}$ The rationale for TID is captured by the first principle of the Guidelines for implementing Article 5.3 of the FCTC: 'there is a fundamental and irreconcilable conflict between the tobacco industry's interests and public health policy interests'. ${ }^{13}$

No previous reviews have specifically examined the effectiveness of TID as a tobacco control strategy. We review evidence on TID and smokingrelated outcomes. We analyse why some findings appear to diverge from the bulk of published literature. The evidence suggests strongly that TID is an effective strategy that should be part of comprehensive tobacco control.

\section{METHODS}

\section{Search}

We searched the PubMed and Scopus databases for articles published through December 2010 using the following search terms: ('Tobacco Industry'(Mesh) OR 'tobacco industry') AND (delegitimization OR delegitimation OR denormalisation OR de-normalisation OR de-normalization OR anti-industry OR counter-industry $\mathrm{OR}$ vilification $\mathrm{OR}$ industry manipulation); 'tobacco industry' AND (deception* OR mistrust* OR lie* OR lying OR false allegation); ('tobacco industry'(Mesh) OR 'tobacco industry' OR tobacco) AND (countermarketing OR counteradvertising); ('tobacco industry'(Mesh) OR 'tobacco industry' OR tobacco OR smoking) AND 'truth campaign'; ('tobacco industry'(Mesh) OR 'tobacco industry' OR tobacco OR smoking) AND (truth OR 'truth campaign'); and ('tobacco industry'(Mesh) OR 'tobacco industry') AND (opinion* OR perception* OR belie* OR 'support for action' OR attitude*) (see figure 1). Peer-reviewed research was included if it measured effects of TID on tobacco-related behaviours, attitudes towards industry and support for tobacco control policy (see figure 1). Studies were included from any country, involving any population that measured smoking or tobacco-industry related outcomes. Exclusion 


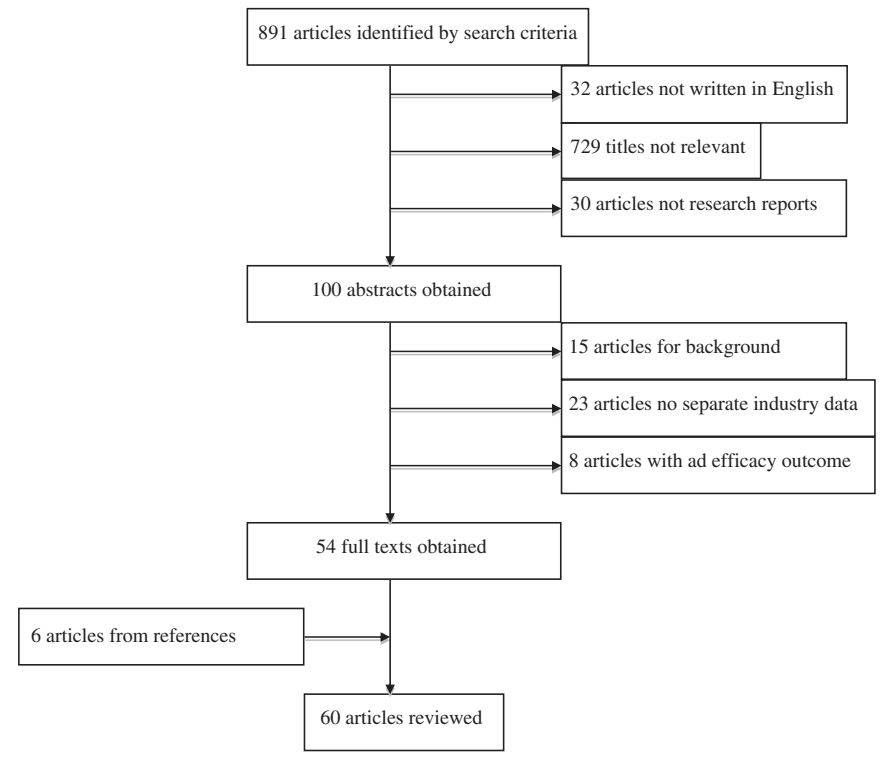

Figure 1 Derivation of 60 articles reviewed from PubMed and Scopus search. The following search strategies were employed: ('Tobacco Industry'[Mesh] OR 'tobacco industry') AND (delegitimization OR delegitimation OR denormalization $\mathrm{OR}$ de-normalization $\mathrm{OR}$ denormalisation $\mathrm{OR}$ anti-industry $\mathrm{OR}$ counter-industry $\mathrm{OR}$ vilification $\mathrm{OR}$ industry manipulation); 'tobacco industry' AND (deception* OR mistrust* OR lie* OR lying OR false allegation); ('tobacco industry'[Mesh] OR 'tobacco industry' OR tobacco) AND (countermarketing OR counteradvertising); ('tobacco industry'[Mesh] OR 'tobacco industry' OR tobacco OR smoking) AND 'truth campaign'; ('tobacco industry'[Mesh] OR 'tobacco industry' OR tobacco OR smoking) AND (truth OR 'truth campaign'); and ('tobacco industry'[Mesh] OR 'tobacco industry') AND (opinion* OR perception* OR belie* OR 'support for action' OR attitude*).

criteria included: non-English language, focus on tobacco use rather than TID, perceived ad efficacy as sole outcome, complex programme interventions without a separately analysable TID component and non-peer-reviewed literature.

The searches yielded 891 articles (figure 1). RM and QG independently identified 54 articles meeting inclusion criteria. LB reviewed discrepancies; final selection was achieved by consensus. Six additional articles were identified from reference lists. QG read the 60 articles and abstracted information using a data collection form.

\section{Analysis}

Studies were grouped for descriptive analysis by type of outcome measured. Six studies used structural equation modelling to theorise links between TID and smoking-related outcomes and were summarised separately.

\section{RESULTS}

\section{Study characteristics}

The 60 articles represented 56 unique studies (table 1). Most were conducted in the US $(n=46 ; 82 \%)$. Several regions and counter-industry campaigns were represented: the national 'truth' campaign ( $n=15)$, the Florida 'truth' campaign $(n=9)$, the Minnesota Initiative, Target Market $(n=3)$, the Wisconsin Campaign $(n=2)$, the Mississippi campaign $(n=1)$ and a media literacy programme in Washington $(n=1)$.

Nine smoking-related outcomes were measured (see table 1). All were measured using self-report. Three studies employed qualitative methodologies. Cross-sectional designs dominated $(n=37 ; 66 \%) ; 23$ of these used repeated measurements. Four studies were longitudinal. There were several quasi-experimental designs: controlled comparison $(n=1)$, controlled before and after $(n=3)$, historically controlled $(n=3)$ and controlled experiment $(n=1)$. Four studies were randomised controlled trials (RCTs).

In all, 38 studies employed random sampling (60\%). The most commonly used sampling frame was a vendor-generated telephone list $(\mathrm{n}=34 ; 54 \%)$. Middle and high schools were the next most common ( $n=10 ; 16 \%)$. Several studies used the same data sets: the Legacy Media Tracking Surveys (LMTS), sponsored by the American Legacy Foundation (ALF) $(n=14)$; the Florida Youth Tobacco Survey (FYTS), sponsored by the Florida state Department of Health $(n=2)$, and the Florida Anti-tobacco Media Evaluation (FAME), through Florida State University $(n=5)$. These data sets were representative of their population; LMTS oversampled racial and ethnic minorities.

Youth aged 12-17 were the focus of most studies $(n=37$; $59 \%$ ). Three used an extended definition of youth: ages $12-25$ years. Five examined young adults, defined as either $18-25$ years $(n=4)$ or $18-29$ years $(n=1)$. A total of 15 studies included adults, 2 requiring adults to have children aged $12-17$. Three studies employed mixed youth/adult samples.

A conflict of interest exists when campaigns are evaluated by implementing agencies. In Florida, the Department of Health contracted for an independent evaluation. ${ }^{14}$ Twelve studies evaluating the national 'truth' campaign were funded by the ALF, 2 by other sources; 3 did not disclose funding. These studies' principal researchers are housed at ALF, RTI International, Centers for Disease Control, American Institute for Research, RAND Corporation and other academic research centres. It appeared that none of the researchers were responsible for data collection through FAME, FYTS or LMTS surveys and many acknowledged external survey management companies.

\section{Smoking prevalence}

TID's relation to smoking prevalence was examined in 13 studies. Measured by self-report, studies most commonly employed 30 day and 100-cigarettes-in-lifetime referents, placing respondents on a $3-5$ classification continuum (table 1 ). This measure is widely used and appropriate for youth and young adults, capturing the construct of smoking initiation and progression to smoking dependence.

\section{Smoking prevalence: youth}

The first youth campaign to be highly funded and thoroughly evaluated was the 'truth' campaign piloted by the state of Florida, launched in April 1998, featuring a strong TID component. Surveys following Florida 'truth's' implementation showed large decreases in smoking prevalence among youth ages $12-17^{14-16}$ and similar decreases for prevalence in all categories along the smoking behaviour continuum. ${ }^{15}$ Prevalence of never users and those defined as committed non-smokers rose significantly. ${ }^{15}$ Less than a year after campaign launch, non-smoking youth who remained non-smokers were 2.3 times more likely than those who started smoking to say they were influenced 'a lot' by the 'truth' campaign's primary, industry manipulation message. ${ }^{14}$

At 2 years into the Florida campaign, national 'truth' was launched, permitting comparisons between Florida and national youth. Florida youth were significantly less likely than national youth to have smoked in the past month, or to have ever tried smoking. ${ }^{17}{ }^{18}$ Florida youth also held less favourable beliefs about the tobacco industry. ${ }^{17}$ Predictive of smoking behaviour in the past 30 days were two beliefs central to the campaign: 'cigarette companies lie' and 'cigarette companies try to get young people to start smoking' ${ }^{17}$ However, 4 years after 
Table 1 Characteristics of included studies

\begin{tabular}{|c|c|c|c|c|}
\hline Author, year, country & $\mathbf{n}$ & Population & Design & Outcomes measured \\
\hline Ashley and Cohen, 2003, Canada ${ }^{54}$ & 1607 & Adult: $18+$ years & Cross-sectional & Attitudes towards tobacco industry (TI) \\
\hline Austin et al, 2005, USA ${ }^{23}$ & 119 & $\begin{array}{l}\text { Youth: } \\
15-25 \text { years }\end{array}$ & $\begin{array}{l}\text { Controlled before and } \\
\text { after }\end{array}$ & $\begin{array}{l}\text { Current smoking prevalence } \dagger ; \text { intent to } \\
\text { smoke } \ddagger \text {; perceived peer prevalence }\end{array}$ \\
\hline Bauer et al, 2000, USA ${ }^{15}$ & $20978-23745$ & $\begin{array}{l}\text { Youth: } \\
12-17 \text { years }\end{array}$ & $\begin{array}{l}\text { Repeated cross-sectional } \\
\text { (three waves) }\end{array}$ & $\begin{array}{l}\text { Current smoking prevalence§; intent to } \\
\text { smoke }\end{array}$ \\
\hline Carver et al, 2003, USA ${ }^{62}$ & 800,790 & $\begin{array}{l}\text { Adult: } 18+\text { with } \\
\text { children }\end{array}$ & Historically controlled & Attitudes towards $\mathrm{TI}$ \\
\hline Cowell et al, 2009, USA ${ }^{37}$ & 31785 & $\begin{array}{l}\text { Youth: } \\
12-17 \text { years }\end{array}$ & $\begin{array}{l}\text { Repeated cross-sectional } \\
\text { (seven waves) }\end{array}$ & Intent to smoke** \\
\hline Danishevski et al, 2008, Russia ${ }^{58}$ & 1600 & Adult: $18+$ years & Cross-sectional & Attitudes towards TI \\
\hline $\begin{array}{l}\text { Davis et al, 2007, USA } \\
\text { Farrelly et al, 2009 }\end{array}$ & 35074 & $\begin{array}{l}\text { Youth: } \\
12-17 \text { years }\end{array}$ & $\begin{array}{l}\text { Repeated cross-sectional } \\
\text { (eight waves) }\end{array}$ & $\begin{array}{l}\text { Intent to smoke; perceived peer smoking } \\
\text { prevalence }\end{array}$ \\
\hline Davis et al, 2009, USA ${ }^{27}$ & 16327 & $\begin{array}{l}\text { Youth: } \\
12-17 \text { years }\end{array}$ & Longitudinal & Smoking initiation; intent to smoke \\
\hline $\begin{array}{l}\text { Dietz et al, 2008, USA } \\
\text { Delva et al, 2009 }\end{array}$ & 2374 & Adult: $18+$ years & Cross-sectional & Intent to quit smoking \\
\hline Dietz et al, 2010, USA ${ }^{16}$ & 14400 & $\begin{array}{l}\text { Youth: } \\
12-17 \text { years }\end{array}$ & $\begin{array}{l}\text { Repeated cross-sectional } \\
\text { (eight waves) }\end{array}$ & Current smoking prevalence $†$ \\
\hline Dixon et al, 2001, Australia ${ }^{42}$ & $\begin{array}{l}323 \text { prior to study, } \\
266 \text { post study }\end{array}$ & $\begin{array}{l}\text { Adult/youth: } \\
15-60 \text { years }\end{array}$ & Controlled before and after & Intent to smoke††; attitudes towards $\mathrm{TI}$ \\
\hline Dunn et al, 2004, USA ${ }^{32}$ & 852 & $\begin{array}{l}\text { Youth: } \\
15-17 \text { years }\end{array}$ & Cross-sectional & Intent to smoke ${ }^{*}$; empowerment \\
\hline Dunn and Pirie, 2005, USA ${ }^{53}$ & 940 & $\begin{array}{l}\text { Youth: } \\
12-25 \text { years }\end{array}$ & Cross-sectional & Empowerment \\
\hline Durkin et al, 2005, Australia ${ }^{55}$ & $1995-3001$ & Adult: $18+$ years & $\begin{array}{l}\text { Repeated cross-sectional } \\
\text { (three waves) }\end{array}$ & Attitudes towards TI \\
\hline Edwards et al, 2007, Australia ${ }^{43}$ & 3091 & $\begin{array}{l}\text { Youth: } \\
12-25 \text { years }\end{array}$ & Historically controlled & Intent to smoke†† \\
\hline $\begin{array}{l}\text { Evans et al, 2002, USA } \\
\text { Evans et al, 2005 }\end{array}$ & 2306 & $\begin{array}{l}\text { Youth: } \\
12-17 \text { years }\end{array}$ & $\begin{array}{l}\text { Repeated cross-sectional } \\
\text { (two waves) }\end{array}$ & Structural equation modelling \\
\hline Evans et al, 2004, USA ${ }^{72}$ & 10412 & $\begin{array}{l}\text { Youth: } \\
12-17 \text { years }\end{array}$ & $\begin{array}{l}\text { Repeated cross-sectional } \\
\text { (three waves) }\end{array}$ & Structural equation modelling \\
\hline Farrelly et al, 2002, USA ${ }^{28}$ & $3439-6233$ & $\begin{array}{l}\text { Youth: } \\
12-17 \text { years }\end{array}$ & $\begin{array}{l}\text { Repeated cross-sectional } \\
\text { (two waves) }\end{array}$ & Intent to smoke** \\
\hline Farrelly et al, 2005, USA ${ }^{22}$ & 43922 & $\begin{array}{l}\text { Youth: } \\
12-17 \text { years }\end{array}$ & Historically controlled & Current smoking prevalence $†$ \\
\hline Farrelly et al, 2009, USA ${ }^{28}$ & 8904 & $\begin{array}{l}\text { Youth: } \\
12-17 \text { years }\end{array}$ & Longitudinal & Smoking initiation; intent to smoke** \\
\hline $\begin{array}{l}\text { Hammond et al, 2006, Canada/US/ } \\
\text { UK/Australia }^{8} \text {, Young et al, } 2007^{46}\end{array}$ & $8222-9058$ & $\begin{array}{l}\text { Adult: } \\
18+\text { years, smoker* }\end{array}$ & $\begin{array}{l}\text { Repeated cross-sectional } \\
\text { (three waves) }\end{array}$ & Intent to quit; attitudes towards $\mathrm{TI}$ \\
\hline Henriksen and Fortmann, 2002, USA ${ }^{66}$ & 218 & $\begin{array}{l}\text { Young adult: } \\
18-25 \text { years }\end{array}$ & Randomised controlled trial & Attitudes towards TI \\
\hline Hersey et al, 2003, USA ${ }^{68}$ & 6875 & $\begin{array}{l}\text { Youth: } \\
12-25 \text { years }\end{array}$ & Cross-sectional & Structural equation modelling \\
\hline Hersey et al, 2005, USA ${ }^{19}$ & 34946 & $\begin{array}{l}\text { Youth: } \\
12-17 \text { years }\end{array}$ & $\begin{array}{l}\text { Repeated cross-sectional } \\
\text { (five waves) }\end{array}$ & Current smoking prevalence $†$ \\
\hline Hersey et al, 2005, USA ${ }^{67}$ & 16464 & $\begin{array}{l}\text { Youth: } \\
12-17 \text { years }\end{array}$ & $\begin{array}{l}\text { Repeated cross-sectional } \\
\text { (three waves) }\end{array}$ & Structural equation modelling \\
\hline Hudson et al, 2007, New Zealand ${ }^{65}$ & 10 & Adult: 18 years & Qualitative interviews & Attitudes towards $\mathrm{TI}$ \\
\hline Johnson et al, 2008, USA ${ }^{60}$ & 28 & $\begin{array}{l}\text { Youth: } \\
12-14 \text { years }\end{array}$ & Qualitative focus groups & Attitudes towards $\mathrm{TI}$ \\
\hline Kim and Nam, 2005, USA ${ }^{63}$ & 22 & $\begin{array}{l}\text { Adult: } 18 \text { years* } \\
\text { smoker }\end{array}$ & Qualitative focus groups & Attitudes towards TI \\
\hline King et al, 2007, USA ${ }^{61}$ & 410 & Adult: $18+$ years $^{*}$ & Cross-sectional & Attitudes towards $\mathrm{TI}$ \\
\hline Klesges et al, 2009, USA ${ }^{26}$ & $\begin{array}{l}36013 \text { prior to study, } \\
20672 \text { post study }\end{array}$ & $\begin{array}{l}\text { Adult: } \\
\text { Air Force Recruits }\end{array}$ & Longitudinal & $\begin{array}{l}\text { Current smoking prevalence§; } \\
\text { smoking initiation }\end{array}$ \\
\hline Leatherdale et al, 2006, Canada ${ }^{21}$ & 14767 & $\begin{array}{l}\text { Youth: } \\
14-18 \text { years }\end{array}$ & Cross-sectional & Current smoking prevalence§ \\
\hline Ling et al, 2007, USA ${ }^{24}$ & 9455 & $\begin{array}{l}\text { Young adult: } \\
18-29 \text { years }\end{array}$ & Cross-sectional & $\begin{array}{l}\text { Current smoking prevalence }{ }^{\text {i }} \\
\text { intent to quit; intent to smoke }\end{array}$ \\
\hline Ling et al, 2009, USA ${ }^{25}$ & 1731 & $\begin{array}{l}\text { Young adult: } \\
18-29 \text { years }\end{array}$ & Cross-sectional & $\begin{array}{l}\text { Current smoking prevalence } † \neq \ddagger \text {; } \\
\text { intent to quit }\end{array}$ \\
\hline $\begin{array}{l}\text { Murphy-Hoefer et al, 2008, USA } \\
\text { Murphy-Hoefer et al, 2010, USA }\end{array}$ & 1011 & $\begin{array}{l}\text { Young adult: } \\
18-24 \text { years }\end{array}$ & Controlled experiment & Intent to quit \\
\hline Netemeyer et al, 2005, USA ${ }^{49}$ & 1207 & $\begin{array}{l}\text { Adult: } 18+\text { years, } \\
\text { smoker }\end{array}$ & Cross-sectional & Intent to quit \\
\hline Niederdeppe et al, 2004, USA ${ }^{17}$ & 7478 & $\begin{array}{l}\text { Youth: } \\
12-17 \text { years }\end{array}$ & $\begin{array}{l}\text { Repeated cross-sectional } \\
\text { (three waves) }\end{array}$ & $\begin{array}{l}\text { Current smoking prevalence } f \text {; intent } \\
\text { to smoke }\end{array}$ \\
\hline
\end{tabular}


Table 1 Continued

\begin{tabular}{|c|c|c|c|c|}
\hline Author, year, country & $\mathbf{n}$ & Population & Design & Outcomes measured \\
\hline Niederdeppe et al, 2008, USA ${ }^{31}$ & 5010 & $\begin{array}{l}\text { Youth: } \\
12-18 \text { years }\end{array}$ & $\begin{array}{l}\text { Repeated cross-sectional } \\
\text { (five waves) }\end{array}$ & Intent to smoke $\neq$ \\
\hline Pechmann et al, 2003, USA ${ }^{38}$ & 1667 & $\begin{array}{l}\text { Youth: } \\
15-18 \text { years }\end{array}$ & Randomised controlled trial & Intent to smoke*; resistance self-efficacy \\
\hline Pechmann et al, 2006, USA ${ }^{39}$ & 1725 & $\begin{array}{l}\text { Youth: } \\
14-15 \text { years }\end{array}$ & Randomised controlled trial & Intent to smoke*; empowerment \\
\hline Reinert et al, 2010, USA ${ }^{64}$ & 53 & $\begin{array}{l}\text { Adult: } \\
\text { School nurses }\end{array}$ & Cross-sectional & Attitudes towards $\mathrm{TI}$ \\
\hline $\begin{array}{l}\text { Shadel et al, 2009, USA } A^{51} \\
\text { Shadel et al, 2010, USA }\end{array}$ & 110 & $\begin{array}{l}\text { Youth: } \\
11-17 \text { years }\end{array}$ & Controlled comparison & Resistance self-efficacy \\
\hline Sly et al, 2000, USA ${ }^{59}$ & 1816 & $\begin{array}{l}\text { Youth: } \\
12-17 \text { years }\end{array}$ & Cross-sectional & Attitudes towards $\mathrm{TI}$ \\
\hline Sly et al, 2001, USA ${ }^{30}$ & 1820 & $\begin{array}{l}\text { Youth: } \\
12-17 \text { years }\end{array}$ & $\begin{array}{l}\text { Repeated cross-sectional } \\
\text { (two waves) }\end{array}$ & Smoking initiation \\
\hline Sly et al, 2005, USA ${ }^{33}$ & $1079-1150$ & $\begin{array}{l}\text { Youth: } \\
12-17 \text { years }\end{array}$ & $\begin{array}{l}\text { Repeated cross-sectional } \\
\text { (four waves) }\end{array}$ & Intent to smoke ${ }^{* *}$ \\
\hline Sutfin et al, 2008, USA ${ }^{40}$ & 488 & $\begin{array}{l}\text { Youth: } \\
15-17 \text { years }\end{array}$ & Randomised controlled trial & Intent to smoke* \\
\hline Tangari et al, 2007, USA ${ }^{34}$ & 1208 adult, 900 youth & Adult/youth & Cross-sectional & Intent to smoke*; intent to quit \\
\hline Thrasher and Jackson, 2006, USA ${ }^{69}$ & 6670 & $\begin{array}{l}\text { Youth: } \\
12-17 \text { years }\end{array}$ & $\begin{array}{l}\text { Repeated cross-sectional } \\
\text { (two waves) }\end{array}$ & Structural equation modelling \\
\hline Thrasher et al, 2006, USA 20 & 10035 & $\begin{array}{l}\text { Youth: } \\
12-17 \text { years }\end{array}$ & $\begin{array}{l}\text { Repeated cross-sectional } \\
\text { (two waves) }\end{array}$ & $\begin{array}{l}\text { Current smoking prevalencet; } \\
\text { intent to smoke* }\end{array}$ \\
\hline Wakefield et al, 1999, Australia ${ }^{56}$ & 808 & Adult: $18+$ years & Cross-sectional & Attitudes towards $\mathrm{TI}$ \\
\hline Waller et al, 2004, Canada ${ }^{57}$ & $\begin{array}{l}10434 \text {, youth, } \\
1607 \text { adult }\end{array}$ & $\begin{array}{l}\text { Adult/youth: } \\
12-18 \text { years }\end{array}$ & $\begin{array}{l}\text { Repeated cross-sectional } \\
\text { (three waves) }\end{array}$ & Attitudes towards $\mathrm{TI}$ \\
\hline Zucker et al, 2000, USA ${ }^{14}$ & $1247-1806$ & $\begin{array}{l}\text { Youth: } \\
12-17 \text { years }\end{array}$ & Repeated cross-sectional & Current smoking prevalence \\
\hline
\end{tabular}

*Intent to smoke measured with three validated items on a five-point Likert scale: 'in the future, you might smoke one puff or more of a cigarette'; 'you might try out cigarette smoking for a while'; 'if one of your best friends were to offer you a cigarette you would smoke it'.

tCurrent smoking prevalence measured using 30 day referent.

‡Intent to smoke measured with one item on a four-point or seven-point scale: 'if your best friend offered you a cigarette, would you smoke it?'.

$\S$ Current smoking prevalence measured on 3-5 classification continuum: never smoker, experimenter, ever smoker, current smoker, former smoker.

-Intent to smoke measured with four items on a five-point scale: 'do you think you will smoke a cigarette soon?'; 'do you think you will smoke a cigarette anytime during the next year?'; 'do you

think you will be smoking cigarettes 5 years from now?'; 'if one of your best friends offered you a cigarette would you smoke it?'.

**Intent to smoke measured with one item on a four-point Likert scale: 'you will smoke a cigarette in the next year'.

††Intent to smoke measured with one item on a seven-point scale: 'do you think you will be smoking cigarettes this time next year?'.

$\neq \neq$ Current smoking prevalence measured using 100-cigarettes referent.

campaign termination a reversal was seen: although most youth were still able to confirm 'truth' campaign awareness, smoking rates for youth had increased $6.8 \%{ }^{16}$

Three studies examined counter-industry media campaign effects on smoking prevalence among a national youth sample. One compared youth smoking among states with long-term funded, recently funded, or no counter-industry campaigns. ${ }^{19}$ The rate of decrease in youth smoking rates in states with established or new campaigns versus those without was nearly double; similarly, odds of current smoking were reduced significantly faster in states with counter-industry campaigns than in those without. ${ }^{19}$ Over time, negative beliefs and attitudes about the tobacco industry showed significantly stronger relationships with smoking status in campaign versus non-campaign states. ${ }^{19}$

In a large, random, national sample of youth ages $12-17$, higher sensation seeking and weaker counter-industry attitudes were independent predictors of current smoking. ${ }^{20}$ The relationship between counter-industry attitudes and smoking behaviour was consistent across risk groups, suggesting that counter-industry messages may be equally effective for high and low risk youth. ${ }^{20}$ In Canada, a school-based survey of high school students showed that decreases in occasional and regular smoking behaviour were significantly related to TID beliefs. ${ }^{21}$
A historically controlled experiment examined the effects of increased exposure to the national 'truth' campaign. ${ }^{22}$ Researchers found a significant inverse relationship between 'truth' exposure and youth smoking prevalence; however, this effect diminished at higher exposure levels. ${ }^{22}$ Researchers concluded that roughly $22 \%$ of the $36 \%$ decline in youth smoking prevalence from 1997 to 2002 was attributable to the national 'truth' campaign. ${ }^{22}$

ALF and the Washington State Department of Health partnered to implement and evaluate a tobacco media literacy curriculum about deceptive industry advertising tactics. ${ }^{23}$ Although the programme had significant effects on other measures of tobacco attitudes, beliefs and behaviours, it had null effects on smoking prevalence. ${ }^{23}$

\section{Smoking prevalence: young adults}

Three cross-sectional studies measured smoking prevalence in young adults. Counter-industry attitudes and beliefs, including support for action against the industry, were strongly, negatively associated with current smoking in all three. ${ }^{24-26}$ Among US Air Force recruits prior to a mandated cessation programme, the strongest predictor of smoking status was attitude towards the tobacco industry. ${ }^{26}$ Along the smoking status continuum, 
former smokers relative to never smokers, experimental smokers relative to never smokers and current smokers relative to former smokers were less likely to agree with the statement 'tobacco companies lied/misled the public'. ${ }^{26}$

\section{Smoking initiation}

Five studies measured smoking initiation. Smoking initiation is generally only applicable in measuring youth smoking behaviours: four of the studies surveyed samples aged 12-20. However, one examined enforced cessation during Basic Military Training as an intervention, which allowed for measurement of relapse/initiation. ${ }^{26}$ Relapse was less likely among baseline smokers who agreed with statements about the industry's deceptive practices. ${ }^{26}$ However, attitude towards the industry was not a significant predictor of smoking initiation between baseline 'never' or 'experimental' smokers. ${ }^{26}$

The relationship between smoking initiation and the national 'truth' campaign was examined in two longitudinal surveys. More frequent 'truth' recall was associated with both decreased likelihood of smoking initiation and tobacco dependence. ${ }^{27}$ Increased cumulative campaign exposure was associated with a $20 \%$ decrease in initiation risk of over a period of 7 years. ${ }^{28}$

Two repeated cross-sectional surveys examined progression of non-smokers to smokers in association with Florida's 'truth' campaign, finding evidence of an inverse relationship between increased exposure to truth and smoking initiation over a period of 22 months. ${ }^{29}$ Rates of smoking initiation for baseline nonsmokers varied inversely with the number of 'truth' ads recalled, the reported influence of the counter-industry theme and the strength of industry manipulation attitudes. ${ }^{29}$ In another study, compared with those unaffected by the campaign, youth reporting low or high anti-industry ad effects were 1.3 and 1.7 times more likely to remain non-smokers by the second survey. ${ }^{30}$

\section{Intention to smoke}

In all, 17 studies measured intention to smoke.

\section{Intention to smoke: youth}

Florida's 'truth' campaign was associated with increases in the proportion of youth ages 12-17 who identified as 'closed to smoking' and experimenters who stated they would not smoke again. ${ }^{15} 31$ Florida teens were also less likely than their national counterparts to be open to future smoking. ${ }^{17}$ However, after the state cut funding for the programme in 1999, trends in non-smoking intentions were significantly reduced. ${ }^{31}$

Two components of the Minnesota counter-industry campaign Target Market (TM) were studied: TM/org (youth organising) and TM/ads (mass media). No significant relationship was found between exposure to $\mathrm{TM}$ /org and intention to smoke. ${ }^{32}$ However, youth with greater intentions to smoke scored significantly lower on certain attitudinal items such as 'teens have been influenced by the tobacco industry'. ${ }^{32}$ Termination of the TM/ads component had negative impacts on prevalence of respondents scoring highly on industry manipulation attitudes/beliefs, and prevalence of participants not intending to smoke in the next year. ${ }^{33}$

A study of Wisconsin's counter-industry themed campaign found that positive attitudes towards the campaign and number of ads seen were significantly, negatively associated with smoking intentions. ${ }^{34}$

In a repeated cross-sectional study during the first 3 years of the national 'truth' campaign, campaign recall was associated with greater odds of youth ages 12-17 ruling out future smoking. ${ }^{35}$ Higher sensation-seeking traits and weaker counterindustry attitudes independently predicted intention to smoke. ${ }^{20}$ Another repeated cross-sectional study of this same population found no statistically significant increase in the percentage of non-smokers saying they probably/definitely would not smoke in the next year; however, six of nine counterindustry and empowerment attitudes were strongly associated with reduced smoking intentions. ${ }^{36}$ Analysis of racial/ethnic data found a significant association between 'truth' exposure and belief and attitude indices, but the impact, though similar for white and African-American youth, was lower for Hispanic youth. ${ }^{37}$ Though most youth across racial/ethnic subgroups do not intend to smoke at baseline (94\%), exposure to 'truth' was associated with 2.0 greater odds of not intending to smoke among never smokers and 5.7 greater odds among ever smokers, across all racial/ethnic subgroups. ${ }^{37}$

A longitudinal study of youth at low and high risk for smoking showed that those exposed to the national 'truth' campaign were more likely to hold anti-smoking beliefs at follow-up, and more frequent 'truth' recall was significantly associated with decreased likelihood of developing openness to smoking, intentions to smoke soon and in 5 years, but not for intentions to smoke within 1 year. $^{27}$

Three studies used RCTs to investigate the effectiveness of different message themes on adolescents' intentions to smoke. ${ }^{38-40}$ These concluded that industry manipulationthemed ads were ineffective in decreasing intentions to smoke. One study randomised 7 th and 10 th grade students $(44 \%$ Hispanic) to eight different ad conditions (two of which could be considered TID-themed) and a control group. ${ }^{38}$ Two TIDthemed ads enhanced health risk severity perceptions. One TID theme positively influenced 10th graders' perceived vulnerability to social disapproval risks. ${ }^{38}$

Ninth grade California students were randomised to nine ad conditions, three of which were 'counter-industry' type. ${ }^{39}$ Among all participants, no ad type lowered intentions to smoke versus the control.

A third study randomised 16 groups of Virginia high school students to 1 of 3 message theme conditions (where 1 was industry manipulation), or a control. ${ }^{40}$ Those viewing ads portraying negative life circumstances of smokers had lower intentions to smoke than either control or industry manipulation ad groups. ${ }^{40}$

\section{Intention to smoke: adults}

Evidence for TID's effects on intention to smoke among adults is less consistent, perhaps because most campaigns targeted youth. No significant association between campaign awareness and intention to not smoke was found for young adults aged 18-24 in relation to the national 'truth' campaign. ${ }^{41}$ However, several specific attitudes/beliefs promoted by 'truth' were associated with intention to not smoke such as, 'I would like to see cigarette companies go out of business'. ${ }^{41}$ Another study surveying general counter-industry attitudes among adults found support for counter-industry action was negatively associated with intention to smoke within the year. ${ }^{25}$

Two controlled before and after studies examined TID and intention to smoke in the context of movies. Surveyed Australian adults viewed The Insider (a film about tobacco industry duplicity) or the control Erin Brokovich (plot analogous but not about tobacco). The The Insider group showed a decline in intentions to smoke at the post-film survey and a divergent trend from the control group for current, former and non-smokers. ${ }^{42}$ However, when late responders were included, these effects were non-significant, suggesting the film's impact may have been transitory. ${ }^{42}$ A historically controlled experiment 
with cinemagoers seeing an industry manipulation-themed advert prior to viewing their film found a greater proportion of non-smoking participants in the intervention group agreed that smoking in movies was 'not OK', but a significantly higher percentage of smokers in the intervention group said they would still be smoking in 12 months. ${ }^{43}$

\section{Intention to quit}

Eight studies ${ }^{8} 2425344144-49$ examined TID's effects on intentions to quit smoking. All used a single-item measure with adults. Several cross-sectional studies found that beliefs about industry deceptiveness were positively related to consideration of quitting, ${ }^{34} 4445$ as was support for counter-industry action. $^{24}{ }^{25}$ Another study found that supporting action against the industry was positively associated with quit intentions, but not with a serious quit attempt. ${ }^{25}$ In a longitudinal study in four Western nations, smokers reporting medium and high TID beliefs were more likely to intend to quit, and although TID beliefs at time 1 did not predict abstinence at time 2, smokers with stronger beliefs at time 2 were more likely to be abstinent than those who beliefs did not increase. ${ }^{8}$

Although exposure to the national 'truth' campaign was not associated with intention to quit smoking among young adults, seven of nine counter-industry belief/attitude items targeted by the 'truth' campaign were associated with intention to quit among young adult smokers. ${ }^{41}$ Awareness of Florida's 'truth' campaign reached approximately $50 \%$ of adults, and the only variable significantly associated with quit intentions was awareness of the industry manipulation theme, independent of parental status. ${ }^{44} 45$ However, in an evaluation of Wisconsin's campaign, beliefs about industry deceptiveness were not significantly related to quitting considerations. ${ }^{49}$

One study examined effectiveness of ad themes on college students' tobacco use, including intention to quit. College students assigned to TID-themed ads were twice as likely to intend to quit as those who viewed social norms ads. ${ }^{47}$

\section{Other outcomes}

Youth generally overestimate perceptions of peer smoking prevalence (PPSP); it may be a precursor to future smoking. ${ }^{50}$ Two studies suggested that TID is associated with lower PPSP. ${ }^{23} 50$ Evidence from two studies of smoking resistance self-efficacy (SRSE), which is predictive of youth smoking, was mixed: TIDthemed ads were associated with lower SRSE scores than ads emphasising the effects of smoking. ${ }^{51}$ However, industry manipulation ads were associated with greater SRSE when they used less, versus more appealing actors. ${ }^{51}$ Explicit industry manipulation messages (vs implicit) were associated with stronger SRSE. ${ }^{52}$ One RCT found that no tested message themes affected SRSE or marketing resistance self-efficacy. ${ }^{38}$ TID-related activities were associated with higher empowerment (the degree to which youth feel they would like to get involved in organising against the tobacco industry and feel youth can make a difference) scores. ${ }^{32} 53$ However, youth with higher intentions to smoke were less likely to believe that youth could be effective. ${ }^{32}$

\section{Attitudes towards industry and its regulation Views of industry}

Across diverse samples, tobacco companies were regarded as dishonest, unethical and less trustworthy than other companies. ${ }^{42}{ }^{54-57}$ Negative views of industry appeared to be increasingly negative over time. ${ }^{55} 57$ Australian smokers had stronger counter-industry beliefs than either Canadian or UK smokers; UK smokers reported weaker counter-industry beliefs than US or Canadian smokers. ${ }^{8}$ A minority of Russian adults felt tobacco companies behaved unethically, despite three-quarters agreeing that tobacco companies definitely or maybe bribed politicians. ${ }^{58}$ Rather than being a TID marker, this behaviour was considered typical for a Russian corporation.

There is some evidence that support for the process of TID is weaker among smokers; ${ }^{42} 54-5659$ however, in one study smokers were polarised on these beliefs. ${ }^{55}$ Smokers from four countries reported relatively strong counter-industry beliefs, especially among the older and more educated. ${ }^{8}$ Women smokers were less likely to report counter-industry beliefs than men. ${ }^{8}$

In a Canadian study, youth appeared less distrustful of tobacco companies than adults, a consistent finding across smoking categories and school grade. ${ }^{57}$ African American youth focus group participants, however, expressed anger at tobacco industry targeting, considering it a form of racism. ${ }^{60}$ A Florida survey found non-smoking youth more likely than smoking youth to espouse counter-industry attitudes. ${ }^{59}$

One cross-sectional study surveyed adult African-Americans' views about black organisations accepting tobacco industry philanthropy. ${ }^{61}$ Despite most agreeing that philanthropy makes the industry money and encourages smoking, one-third said it also helps the community. ${ }^{61}$ Those with college educations and men were less likely to find this philanthropy acceptable; younger adults were less likely to agree that this philanthropy aimed to help communities. ${ }^{61}$

\section{Views of regulation}

There were varied opinions ranging from neutral to strong beliefs about industry responsibility for smokings' harms and its regulation. Descriptive research has assessed attitudes towards tobacco industry regulation in diverse samples including: adults in Ontario; ${ }^{54}$ Mississippi parents before and after a youthtargeted, counter-industry state media campaign; ${ }^{62}$ Korean immigrant, male smokers; ${ }^{63}$ school nurses ${ }^{64}$ and New Zealand politicians. ${ }^{65}$ In a sample of smokers in four countries, thinking about the conduct of tobacco companies and belief that the industry should take more responsibility for tobacco's harms were independently predictive of support for industry regulation, ${ }^{46}$ and counter-industry beliefs were associated with noticing anti-smoking information, tobacco ads and secondhand smoke restrictions. ${ }^{8}$

\section{Experimental studies: attitudes about industry}

Two experimental studies examined how an intervention could shape perceptions of the industry. Public perceptions of the tobacco industry were assessed using a controlled before-andafter design, with the movie The Insider as the intervention. ${ }^{42}$ Post test, subjects viewing The Insider rated tobacco industry executives lower on ethics and honesty and higher on power held more negative views of industry conduct and showed less acceptance of the industry than controls. ${ }^{42}$ An RCT investigated effects of perceptions of Philip Morris (PM) as a tobacco company on evaluations of the company's advertising among undergraduates. ${ }^{66}$ There was no association between students' opinion of PM and awareness that it is a tobacco company; however, PM corporate advertisements were rated more favourably by students unaware of this fact. ${ }^{66}$

\section{Theorising TID}

Six studies employed structural equation modelling to theorise TID's effects. One model suggested knowledge of industry deception leads to mistrust of the industry, which in turn is associated with support for action against the industry and reduced receptivity to advertising. ${ }^{24}$ Models derived from 
counter-industry campaign data show that TID exposure leads to negative beliefs about the industry's conduct, predicting negative attitudes towards the industry; these are associated with lesser progression towards smoking and reduced receptivity to pro-tobacco influences. ${ }^{67} 68$ Mistrust of the industry appears to strongly influence negative attitudes towards the industry, which in turn explains significant variability in smoking behaviour, suggesting these campaigns succeed because they resonate with trust-related values. ${ }^{69}$ Social imagery, perceived tobacco independence and brand equity have also been shown to mediate the relationship between current smoking and exposure to the national 'truth' campaign. ${ }^{70-72}$

\section{DISCUSSION}

A robust body of evidence supports TID as an effective population-level tobacco control strategy that contributes to reduced smoking prevalence among youth and young adults, reduced smoking initiation among youth, increased intentions to quit and reduced perceived peer smoking prevalence. Evidence is mixed on TID's impact on intentions to smoke, youth empowerment and views of the industry and its regulation, but evidence from California suggests TID's importance as part of a comprehensive social norm change programme. ${ }^{2}$

\section{Limitations}

Because TID is not yet an established indexing term, we may have missed relevant studies. We reluctantly excluded literature on California's landmark programme, the first to feature a strong TID component, because published reports merged TID and other social norm change components into a single construct; these could not be separately analysed. However, California programme evaluations suggest that TID has been an important element in increasing quitting, reducing smoking prevalence and increasing support for tobacco control. ${ }^{2} 3$ 73-76 Heterogeneity in TID interventions and outcome measures did not allow quantitative analyses. Most evidence is from cross-sectional studies, limiting the ability to draw causal conclusions. Most were US studies; national/cultural differences in attitudes towards industry and regulation could limit generalisability.

\section{Interpreting contradictory trials findings}

The RCTs' failure to find an association between TID and intent to smoke may be because the intensity and duration of the interventions were less than in observational studies. Processing of TID-related ads may require additional exposures. ${ }^{40}$ Experimental studies may not capture TID's true effectiveness. In Sutfin's study, ${ }^{40}$ the only ad type associated with decreased intention to smoke was also the only type that participants reported having previously seen, suggesting that repeated exposures might increase intervention effectiveness.

In addition, trials did not consistently control for understanding of the intervention. In one study, only $34 \%$ of participants correctly identified TID ads. ${ }^{40}$ However, this was not included as a covariate for the outcome of intention to smoke. In larger studies, ${ }^{38} 39$ most students recalling ads correctly identified themes.

None of these studies reported absolute numbers of participants expressing intention to smoke. Although Pechmann ${ }^{38} 39$ reported that only one of nine ad types tested had a significant effect on smoking intent compared to control, differences between ad types appeared small, making it difficult to determine if there were meaningful differences in proportions of participants expressing intentions to smoke. It may also be that TID interventions are simply less effectively delivered at the individual level

\section{Research gaps}

Many important questions remain unanswered by existing TID-related research. For example, the cost effectiveness of TID programmes relative to other tobacco control interventions remains largely unstudied. A cost-utility analysis of the national 'truth' campaign estimated that the campaign recovered the costs of development, delivery, evaluation and litigation, and averted nearly US $\$ 1.9$ billion in smoking-related medical costs. ${ }^{77}$ However, the cost effectiveness of such mass media TID interventions compared with other tobacco control interventions is unknown. Similarly, comparative studies are needed to analyse potentially synergistic effects of TID and other tobacco control interventions; whether TID interventions are a necessary component of comprehensive tobacco control; and whether they have an additional effect once other components are in place.

Three existing comparative studies tested the national 'truth' campaign against the Philip Morris-sponsored youth smoking prevention programme, 'Think Don't Smoke'. 27353650 Whereas the 'truth' campaign was associated with an increase in antitobacco beliefs and attitudes, ${ }^{27} 3536$ 'Think Don't Smoke' was associated with an increase in favourable attitudes towards the tobacco industry. ${ }^{35} 36$ Similarly, the 'truth' campaign was associated with decreased perceived smoking prevalence, ${ }^{50}$ decreased intentions to smoke and lower rates of smoking initiation, ${ }^{27}$ while 'Think Don't Smoke' was associated with increased intentions to smoke soon. ${ }^{27}$ Arguably, an industry-sponsored programme does not offer a fair comparison, so studies aimed at teasing out certain effects of TID as compared with other programme components may be useful. However, TID is also likely to have broader, indirect effects on the policy climate, which constitutes another important area for research.

Most reviewed studies involved mass media interventions; however, TID does not only consist of or work through such relatively expensive interventions, but through wider tobacco control advocacy efforts, such as through earned or unpaid media. ${ }^{78-81}$ It is difficult, if not impossible, to fully and explicitly account for such efforts, which change the public discourse about tobacco use by reframing it away from individual behaviour change towards industry regulation.

\section{What this paper adds}

Tobacco industry denormalisation (TID), a focus of successful tobacco control initiatives in the United States and elsewhere, is increasingly regarded as essential to effectively addressing tobacco at the population level. However, TID is not an established indexing term and its effects are challenging to measure. No previous reviews have examined the existing literature on the effectiveness of TID as a tobacco control strategy.

- This review analyzes the evidence on TID's effects on smoking prevalence, smoking initiation, intention to smoke, intention to quit, attitudes toward the tobacco industry and its regulation and other outcomes.

- Robust evidence, summarised here for the first time, shows that TID is an effective tobacco control intervention at the population level. 


\section{Conclusion}

Unpacking why TID is an effective tobacco control intervention is complex methodologically and theoretically. ${ }^{82}$ TID's effectiveness is likely due to synergies between myriad political and cultural influences that cannot be isolated. ${ }^{83}$ The evidence suggests that TID is most effectively delivered at the population level and that increased exposure is generally associated with increased effects. Regardless of how TID works, the industry's aggressive responses suggest that TID passes the 'scream test', constituting a threat to the industry's legitimacy and its continued success in normalising its business, its marketing, and its products. ${ }^{1} 1184-88$ TID may contribute to efforts to 'directly erode industry power', making tobacco companies less able to thwart effective tobacco control. ${ }^{89}$ TID could also enhance public support and political will to counter industry 'makeover' efforts and tackle fundamental structural reforms to end the tobacco epidemic. ${ }^{7}$ 90-93

Funding National Cancer Institute, Grant Number CA120138 (REM); Flight Attendants' Medical Research Institute (LAB).

\section{Competing interests None}

Contributors RM originated the idea for the paper, reviewed studies, analysed findings, wrote sections of the paper and reviewed and edited all drafts. OG retrieved data, reviewed studies, analysed findings, developed tables and figures, wrote the first draft of the paper, and reviewed and edited all drafts. LB reviewed studies, analysed findings, wrote paper sections, and reviewed and edited all drafts.

Provenance and peer review Commissioned; externally peer reviewed.

\section{REFERENCES}

1. Chapman S. Public Health Advocacy and Tobacco Control: Making Smoking History. Oxford, UK: Blackwell Publishing, 2007.

2. Roeseler A, Burns D. The quarter that changed the world. Tob Control 2010;19 (Suppl 1):i3-15.

3. Tang H, Abramsohn E, Park H-Y, et al. Using a cessation-related outcome index to assess California's cessation progress at the population level. Tob Control 2010;19 (Suppl 1):i56-61.

4. Pierce JP, Gilpin EA, Emery SL, et al. Tobacco Control in California: Who's Winning the War? An Evaluation of the Tobacco Control Program, 1989-1996. La Jolla, CA: University of California San Diego, 1998.

5. LeGresley E. A 'vector analysis' of the tobacco epidemic. Medicus Mundi Schweiz 1999;72.

6. World Health Organization. Tobacco Industry Interference with Tobacco Control. Geneva, Switzerland: World Health Organization, 2009.

7. Callard C, Thompson D, Collishaw N. Transforming the tobacco market: why the supply of cigarettes should be transferred from for-profit corporations to non-profit enterprises with a public health mandate. Tob Control 2005;14:278-83.

8. Hammond D, Fong GT, Zanna MP, et al. Among smokers from four countries. Am J Prev Med 2006;31:225-32.

9. World Health Organization. Framework Convention on Tobacco Control. Geneva, Switzerland: World Health Organization, 2003.

10. Glantz S, Balbach ED. Tobacco War: Inside the California Battles. Berkeley, CA University of California Press, 2000.

11. Apollonio DE, Malone RE. Turning negative into positive: public health mass media campaigns and negative advertising. Health Educ Res 2009;24:483-95.

12. Mahood G. Tobacco Industry Denormalization: Telling the Truth About the Tobacco Industry's Role in the Tobacco Epidemic. Canada: Nonsmokers' Rights Association, 2004.

13. WHO Framework Convention on Tobacco Control. Guidelines for Implementation of Article 5.3 of the WHO Framework Convention on Tobacco Control. Geneva, Switzerland: World Health Organization (WHO), 2008.

14. Zucker D, Hopkins RS, Sly DF, et al. Florida's "truth" campaign: a counter-marketing, anti-tobacco media campaign. J Public Health Manag Pract 2000;6:1-6.

15. Bauer UE, Johnson TM, Hopkins RS, et al. Changes in youth cigarette use and intentions following implementation of a tobacco control program: findings from the Florida Youth Tobacco Survey, 1998-2000. JAMA 2000;284:723-8.

16. Dietz NA, Westphal $\mathrm{L}$, Arheart $\mathrm{KL}$, et al. Changes in youth cigarette use following the dismantling of an antitobacco media campaign in Florida. Prev Chronic Dis 2010;7:A65

17. Niederdeppe J, Farrelly MC, Haviland ML. Confirming "truth": more evidence of a successful tobacco countermarketing campaign in Florida. Am J Public Health 2004;94:255-7

18. Sly DF, Heald GR, Ray S. The Florida "truth" anti-tobacco media evaluation: design, first year results, and implications for planning future state media evaluations. Tob Control 2001;10:9-15.
19. Hersey JC, Niederdeppe J, Ng SW, et al. How state counter-industry campaigns help prime perceptions of tobacco industry practices to promote reductions in youth smoking. Tob Control 2005;14:377-83.

20. Thrasher JF, Niederdeppe JD, Jackson C, et al. Using anti-tobacco industry messages to prevent smoking among high-risk adolescents. Health Educ Res 2006;21:325-37.

21. Leatherdale ST, Sparks R, Kirsh VA. Beliefs about tobacco industry (mal)practices and youth smoking behaviour: insight for future tobacco control campaigns (Canada). Cancer Causes Control 2006;17:705-11.

22. Farrelly MC, Davis KC, Haviland ML, et al. Evidence of a dose-response relationship between "truth" antismoking ads and youth smoking prevalence. Am J Public Health 2005:95:425-31

23. Austin EW, Pinkleton BE, Hust SJ, et al. Evaluation of an American Legacy Foundation/Washington State Department Of Health Media Literacy Pilot Study. Health Commun 2005;18:75-95.

24. Ling PM, Neilands TB, Glantz SA. The effect of support for action against the tobacco industry on smoking among young adults. Am J Public Health 2007; 97:1449-56.

25. Ling PM, Neilands TB, Glantz SA. Young adult smoking behavior: a national survey Am J Prev Med 2009;36:389-94 e2.

26. Klesges RC, Sherrill-Mittleman DA, Debon M, et al. Do we believe the tobacco industry lied to us? Association with smoking behavior in a military population. Health Educ Res 2009;24:909-21.

27. Davis KC, Farrelly MC, Messeri $\mathrm{P}$, et al. The impact of national smoking prevention campaigns on tobacco-related beliefs, intentions to smoke and smoking initiation: results from a longitudinal survey of youth in the United States. Int J Environ Res Public Health 2009;6:722-40.

28. Farrelly MC, Nonnemaker J, Davis KC, et al. The Influence of the National truth campaign on smoking initiation. Am J Prev Med 2009;36:379-84.

29. Sly DF, Trapido E, Ray S. Evidence of the dose effects of an antitobacco counteradvertising campaign. Prev Med 2002;35:511-18.

30. Sly DF, Hopkins RS, Trapido E, et al. Influence of a counteradvertising media campaign on initiation of smoking: the Florida "truth" campaign. Am J Public Health 2001;91:233-8.

31. Niederdeppe J, Farrelly MC, Hersey JC, et al. Consequences of dramatic reductions in state tobacco control funds: Florida, 1998-2000. Tob Control 2008:17:205-10.

32. Dunn CL, Pirie PL, Oakes JM. Outcomes of a statewide anti-tobacco industry youth organizing movement. Am J Health Promot 2004:19:3-11.

33. Sly DF, Arheart K, Dietz N, et al. The outcome consequences of defunding the Minnesota youth tobacco-use prevention program. Prev Med 2005;41:503-10.

34. Tangari AH, Burton S, Andrews JC, et al. How do antitobacco campaign advertising and smoking status affect beliefs and intentions? Some similarities and differences between adults and adolescents. J Publ Pol Market 2007:26:60-74.

35. Farrelly MC, Davis KC, Duke J, et al. Sustaining 'truth': changes in youth tobacco attitudes and smoking intentions after 3 years of a national antismoking campaign. Health Educ Res 2009;24:42-8.

36. Farrelly MC, Healton CG, Davis KC, et al. Getting to the truth: evaluating national tobacco countermarketing campaigns. Am J Public Health 2002;92:901-7.

37. Cowell AJ, Farrelly MC, Chou R, et al. Assessing the impact of the national 'truth' antismoking campaign on beliefs, attitudes, and intent to smoke by race/ethnicity. Ethn Health 2009;14:75-91.

38. Pechmann C, Zhao G, Goldberg ME, et al. What to convey in anti-smoking advertisements for adolescents: the use of protection motivation theory to identify effective message themes. J Market 2003;67:1-18.

39. Pechmann C, Reibling ET. Antismoking advertisements for youths: an independent evaluation of health, counter-industry, and industry approaches. Am J Public Health 2006:96:906-13

40. Sutfin EL, Szykman LR, Moore MC. Adolescents' responses to anti-tobacco advertising: exploring the role of adolescents' smoking status and advertisement theme. J Health Commun 2008:13:480-500.

41. Richardson $\mathbf{A K}$, Green $\mathrm{M}, \mathrm{Xia0} \mathrm{H}$, et al. Evidence for truth ${ }^{\circledR}$ the young adult response to a youth-focused anti-smoking media campaign. Am J Prev Med 2010;39:500-6.

42. Dixon HG, Hill DJ, Borland R, et al. Public reaction to the portrayal of the tobacco industry in the film the Insider. Tob Control 2001;10:285-91.

43. Edwards C, Oakes W, Bull D. Out of the smokescreen II: will an advertisement targeting the tobacco industry affect young people's perception or smoking in movies and their intention to smoke? Tob Control 2007:16:177-81.

44. Delva J, Dietz NA, Perron B, et al. Adult awareness of a youth-focused anti-tobacco campaign: does having children matter? Subst Use Misuse 2009;44:763-74.

45. Dietz NA, Delva J, Woolley ME, et al. The reach of a youth-oriented anti-tobacco media campaign on adult smokers. Drug Alcohol Depend 2008;93:180-4.

46. Young D, Borland R, Siahpush M, et al. Australian smokers support stronger regulatory controls on tobacco: findings from the ITC Four-Country Survey. Aust N Z J Public Health 2007;31:164-9.

47. Murphy-Hoefer R, Hyland A, Higbee C. Perceived effectiveness of tobacco countermarketing advertisements among young adults. Am J Health Behav 2008;32:725-34.

48. Murphy-Hoefer R, Hyland A, Rivard C. The influence of tobacco countermarketing ads on college students' knowledge, attitudes, and beliefs. J Am Coll Health 2010;58:373-81. 
49. Netemeyer RG, Andrews JC, Burton S. Effects of antismoking advertising-based beliefs on adult smokers' consideration of quitting. Am J Public Health 2005;95:1062-66

50. Davis KC, Nonnemaker JM, Farrelly MC. Association between national smoking prevention campaigns and perceived smoking prevalence among youth in the United States. J Adolesc Health 2007:41:430-6.

51. Shadel WG, Fryer CS, Tharp-Taylor S. Uncovering the most effective active ingredients of antismoking public service announcements: the role of actor and message characteristics. Nicotine Tob Res 2009:11:547-52.

52. Shadel WG, Fryer CS, Tharp-Taylor S. Tobacco industry manipulation messages in anti-smoking public service announcements: the effect of explicitly versus implicitly delivering messages. Addict Behav 2010;35:526-9.

53. Dunn CL, Pirie PL. Empowering youth for tobacco control. Am J Health Promot 2005:20:7-10.

54. Ashley MJ, Cohen JE. What the public thinks about the tobacco industry and its products. Tob Control 2003;12:396-400.

55. Durkin SJ, Germain D, Wakefield M. Adult's perceptions about whether tobacco companies tell the truth in relation to issues about smoking. Tob Control 2005; 14:429-30.

56. Wakefield M, Miller C, Woodward S. Community perceptions about the tobacco industry and tobacco control funding. Aust N Z J Public Health 1999;23:240-4.

57. Waller BJ, Cohen JE, Ashley MJ. Youth attitudes towards tobacco control: a preliminary assessment. Chronic Dis Can 2004;25:97-100.

58. Danishevski K, Gilmore A, McKee M. Public attitudes towards smoking and tobacco control policy in Russia. Tob Control 2008;17:276-83.

59. Sly DF, Heald G, Hopkins RS, et al. The industry manipulation attitudes of smokers and nonsmokers. J Public Health Manag Pract 2000;6:49-56.

60. Johnson DM, Wine LA, Zack $S$, et al. Designing a tobacco counter-marketing campaign for African American youth. Tob Induc Dis 2008;4:7

61. King G, Gebreselassie T, Mallett RK, et al. Opinions of African Americans about tobacco industry philanthropy. Prev Med 2007:45:464-70.

62. Carver V, Reinert B, Range LM, et al. Media campaign influences parents' opinions about their children and tobacco. J Public Health Manage Pract 2003;9:72-8.

63. Kim SS, Nam KA. Korean male smokers' perceptions of tobacco control policies in the United States. Public Health Nurs 2005;22:221-9.

64. Reinert B, Carver V, Range LM. School nurses' opinions about the prevention of tobacco use. J Community Health Nurs 2005;22:205-11.

65. Hudson S, Thomson G, Wilson N. A pilot qualitative study of New Zealand policymakers' knowledge of, and attitudes to, the tobacco industry. Aust New Zealand Health Policy 2007; 4:17

66. Henriksen L, Fortmann SP. Young adults' opinions of Philip Morris and its television advertising. Tob Control 2002:11:236-40.

67. Hersey JC, Niederdeppe J, Evans WD, et al. The theory of "truth": how counterindustry media campaigns affect smoking behavior among teens. Health Psychol 2005:24:22-31.

68. Hersey JC, Niederdeppe J, Evans WD, et al. The effects of state counterindustry media campaigns on beliefs, attitudes, and smoking status among teens and young adults. Prev Med 2003;37:544-52.

69. Thrasher JF, Jackson C. Mistrusting companies, mistrusting the tobacco industry: clarifying the context of tobacco prevention efforts that focus on the tobacco industry. J Health Soc Behav 2006;47:406-22.

70. Evans WD, Wasserman J, Bertolotti E, et al. Branding behavior: the strategy behind the truth campaign. Soc Mark 0 2002;8:17-29.
71. Evans WD, Price S, Blahut S. Evaluating the truth brand. J Health Commun 2005; 10:181-92

72. Evans WD, Price $\mathrm{S}$, Blahut $\mathrm{S}$, et al. Social imagery, tobacco independence, and the truthsm campaign. J Health Commun 2004:9:425-41.

73. Cowling DW, Modayil MV, Stevens C. Assessing the relationship between ad volume and awareness of a tobacco education media campaign. Tob Control 2010;19(Suppl 1):i37-42

74. Zhang $\mathbf{X}$, Cowling DW, Tang $\mathrm{H}$. The impact of social norm change strategies on smokers' quitting behaviours. Tob control 2010:19(Suppl 1):i51-5.

75. Park HY, Dent C, Abramsohn E, et al. Evaluation of California's in-school tobacco use prevention education (TUPE) activities using a nested school-longitudinal design, 2003-2004 and 2005-2006. Tob Control 2010;19(Suppl 1):i43-50.

76. Modayil MV, Cowling DW, Tang $\mathrm{H}$, et al. An evaluation of the California community intervention. Tob Control 2010;19(Suppl 1):i30-6.

77. Holtgrave DR, Wunderink KA, Vallone DM, et al. Cost-utility analysis of the National truth campaign to prevent youth smoking. Am J Prev Med 2009;36:385-8.

78. Christofides $\mathbf{N}$, Chapman S, Dominello A. The new pariahs: discourse on the tobacco industry in the Sydney press, 1993-97. Aust N Z J Public Health 1999;23:233-9.

79. Chapman S. The news on tobacco control: time to bring the background into the foreground. Tob Control 1999;8:237-9.

80. McLeod K, Wakefield M, Chapman S, et al. Changes in the news representation of smokers and tobacco-related media advocacy from 1995 to 2005 in Australia. $J$ Epidemiol Community Health 2009:63:215-20.

81. Miller CL, Hill DJ, Quester PG, et al. Response of mass media, tobacco industry and smokers to the introduction of graphic cigarette pack warnings in Australia. Eur $\mathrm{J}$ Public Health 2009;19:644-9.

82. Agostinelli G, Grube JW. Tobacco counter-advertising: a review of the literature and a conceptual model for understanding effects. J Health Commun 2003;8:107-27.

83. Chapman S, Freeman B. Markers of the denormalisation of smoking and the tobacco industry. Tob Control 2008;17:25-31.

84. Balbach ED, Glantz SA. Tobacco control advocates must demand high-quality media campaigns: the California experience. Tob Control 1998:7:397-408.

85. Ibrahim JK, Glantz SA. Tobacco industry litigation strategies to oppose tobacco control media campaigns. Tob Control 2006;15:50-8.

86. Ibrahim JK, Glantz SA. The rise and fall of tobacco control media campaigns, 1967 2006. Am J Public Health 2007;97:1383-96.

87. McDaniel PA, Malone RE. The role of corporate credibility in legitimizing disease promotion. Am J Public Health 2009;99:452-61.

88. Mandel LL, Bialous SA, Glantz SA. Avoiding "truth": tobacco industry promotion of life skills training. J Adolesc Health 2006;39:868-79.

89. Thomson G, Wilson N. Directly eroding tobacco industry power as a tobacco contro strategy: lessons for New Zealand? N Z Med J 2005;118:U1683.

90. Smith EA, Malone RE. Altria means tobacco: Philip Morris's identity crisis. Am J Public Health 2003;93:553-6.

91. Borland R. A strategy for controlling the marketing of tobacco products: a regulated market model. Tob Control 2003;12:374-82.

92. Gilmore AB, Branston JR, Sweanor D. The case for OFSMOKE: how tobacco price regulation is needed to promote the health of markets, government revenue and the public. Tob Control 2010;19:423-30.

93. Smith EA, Malone RE. Thinking the "unthinkable": why Philip Morris's considered quitting. Tob Control 2003;12:208-13.

\section{The tobacco industry is not a 'normal' business, so let us stop treating it that way: invited commentary}

The global tobacco industry kills six million people every year. It does this in a deliberate, systematic manner, complete with business plans, lobbying, political contributions and favours, and cash bonuses to its executives who kill the most people by successfully selling them their deadly cigarettes and other tobacco products.

Six million people. Every year. When one repeats those phrases, slowly and aloud-six million people, every year-it seems astounding that Malone et al, ${ }^{1}$ in this issue of Tobacco Control, need, at this late date, to present compelling data calling for the denormalisation of the tobacco industry. Yet the industry still walks among us and kills its users with relative impunity throughout the world. Why is this? Why has there not been greater public outrage and the political will necessary to end the scourge of the tobacco industry?

There are likely many answers, but consider these few:

- Tobacco use is considered by many smokers to have been a personal choice and a personal failing, making it embarrassing for them or their families to stand up to the tobacco industry.

- Most victims of tobacco-caused disease die and disappear quickly, limiting their opportunity to confront the tobacco industry.

- The tobacco pandemic has developed slowly and insidiously, over more than a century, making the tobacco industry appear just a normal business. 